readily accept that seed production in tropical regions may be more frequent than we implied, but we do not feel that this affects the argument in our article. We did take into aecount the possibility that sweet potato seeds had reached Polynesia, and cited Purseglove's suggestion that the capsules would float. If South American sweet potatoes do habitually produce seod, and if this seed is capable of long distance dispersal, our contention, that it is not necessary to postulate early trans-Pacific voyages to account for the distribution of the cultigens common to both sides of the Pacific Ocean, is reinforced rather than weakened.

Department of Agricultural Botany,

University of Reading.

\section{Sex Expression and the Production of Ethylene induced by Auxin in the Cucumber (Cucumis sativum $\mathbf{L}$.)}

Laibach and Kribben ${ }^{2}$ and others ${ }^{2,3}$ have reported altering the sex expression of monoecious cucumber plants by applying auxins to growing plants. The treatments increased the ratio of fernale to male flowers. A considerable change toward femaleness in cucumbers was reported ${ }^{4}$ as a rosult of a single treatment with 2 -chloroethylphosphonic acid (CEPA), which causes the release of ethylene. There are reports that the production of ethylene is induced in many plauts after treatment with indoleacetic acid $(\mathrm{IAA})^{6,7}$ or naphthaleneacetic acid (NAA) ${ }^{8}$. We have evidence that cucumber plants treated with auxins or CEYA also produce ethylene, which, we suggest, alters the sex expression of the treated plants.

Cucumber plants (variety Wisconsin SMR-18) wcre grown in a greenhouse at temperatures of $20^{\circ}$ to $28^{\circ} \mathrm{C}$ for 37 days before treatment. The plants had three expanded true leaves at this time and were sprayed with $5 \mathrm{ml}$. of water solutions of IAA, NAA or CEPA with $0 \cdot 1$ per cent 'Tween $20^{\prime}$ as a wetting agent. Check plants were sprayed with solutions of the wetting agent alone. After the plants had dried, bottomless 21 . glass bottles fitted with rubber septum caps were placed over them. The chambers were forced into the soil around the plants and scaled by moistening the soil. The covered plants were kept in the laboratory during the measurement period at $24^{\circ} \pm 2^{\circ} \mathrm{C}$. Samples wore taken for estimation of ethylene at $24 \mathrm{~h}$ intervals, after each of which the glass covers were removed for 15 min to ventilate the plants. The samples were taken with a gas tight syringe and ethylene was determined with a gas chromatograph with hydrogen flame detector and activated alumina column using helium carrier gas.

No ethyleno was detected in any of the control plants during the 5 day measurement period but, as Table 1 shows, ethylene was produced by plants treated with I $\triangle A$, NAA or CEPA, and tho rate of production increased with increasing concentration of NAA. Plants treated with 1,000 p.p.m. of NAA died shortly after the measurement period and those treated with 100 p.p.m. were severely damaged, with leaf epinasty and twistcd stems. Plants treated with 200 p.p.m. of CEPA produced the most ethylene and had some leaf epinasty and grew a little more

Table 1. ETHYIENE PRODUCED BY CUCUMBER PLANTS SPRAYED WTTH

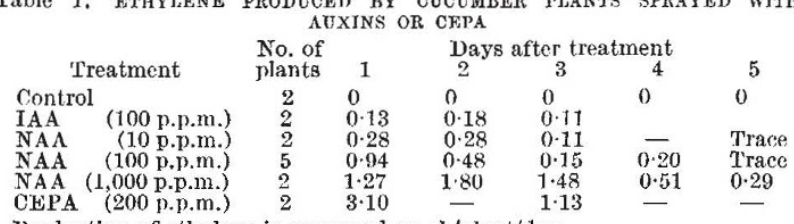

Production of ethylene is measured as $\mu \mathrm{l}$./plant/day. slowly than the other plants, but they were healthy in other respects. Thus ethylene is not responsible for all of the formative effects of NAA. The ethylene released in the plant by CEPA is thought to be responsible for most if not all of the biological activity associated with applications of CEPA ${ }^{5}$.

A 200 p.p.m. application of CEPA is sufficient to eliminate all male flowers and to cause female flowers to develop on the first ten nodes. The initial rate of ethylene production with this treatment was ten times greater than if 10 p.p.m. of NAA was used. The low rate and short duration of ethylene production by plants treated with 10 p.p.m. of NAA would account for the need for repeated applications to accomplish complete sex reversal ${ }^{3}$.

\section{Stanton Shannon}

Manuet D. de la Guardia

Department of Vegetable Crops,

New York State Agricultural

Experiment Station,

Geneva, New York 14456.

Received May 2, 1969.

${ }^{1}$ Laibach, F., and Kribben, F. J., Ber. Deutsch. Bot. Ges., 62, 53 (1949); ibid., 68, $119(1950)$

${ }^{2}$ Rehm, S., Nature, 170, 38 (1952).

${ }^{3}$ Ito, H., and Saito, T., J. Hort. Assoc. Japan, 25, 101 (1956)

4 Robinson, R. W., Bioscience, 19, 141 (1969).

${ }^{3}$ Cooke, A. R., and Randall, D. I., Nature, 218, 974 (1968).

'Zimmerman, P. W., and Wilcoxon, F., Contrib. Boyce Thompson Inst., 7, 209 (1935).

'Morgan, P. W., and Hall, W. C., Nature, 201, 99 (1964).

${ }^{8}$ Burg, S. P., and Burg, E. A., Science, 152, 1269 (1966).

\section{Occurrence of Asexual Reproduction by Budding in Sipunculida}

SIPUNCULID worms are unisexual or hermaphroditic and they only reproduce sexually ${ }^{1,2}$. Ascxual reproduction by budding, which is common among the annelids ${ }^{3,4}$, has not so far been recorded for sipunculids ${ }^{5}$, but we have recently observed asexual reproduction by budding in Sipunculus robustus.

A few of these worms were kept in an aquarium containing stale seawater without sand in our laboratory. In four out of twelve worms it was noticed that the posterior two thirds of the body became narrow and developed wrinkles. These worms were one and a half times longer than usual. Sixteen hours after, a second head developed noar tho middle of the body (Fig. 1). The posterior part together with the new head finally separated as a free individual $46 \mathrm{~h}$ later.

The first sign of a now head in the mid region of the body was the appearance of epidermal thickening in the form of a girdle, bounded above and below by narrow constrictions. The region lying immediately above the

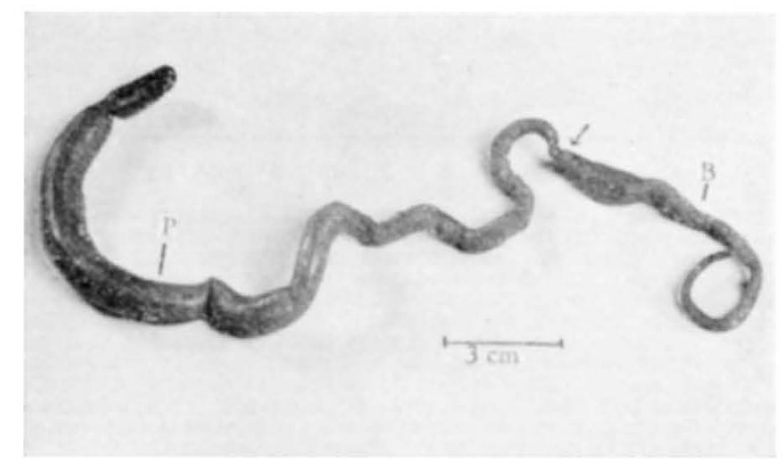

Fig. 1. Sipunculus robustus with bud. The arrow indicates the position of the new head. $B$, Bud; $P$, parent individual. 